
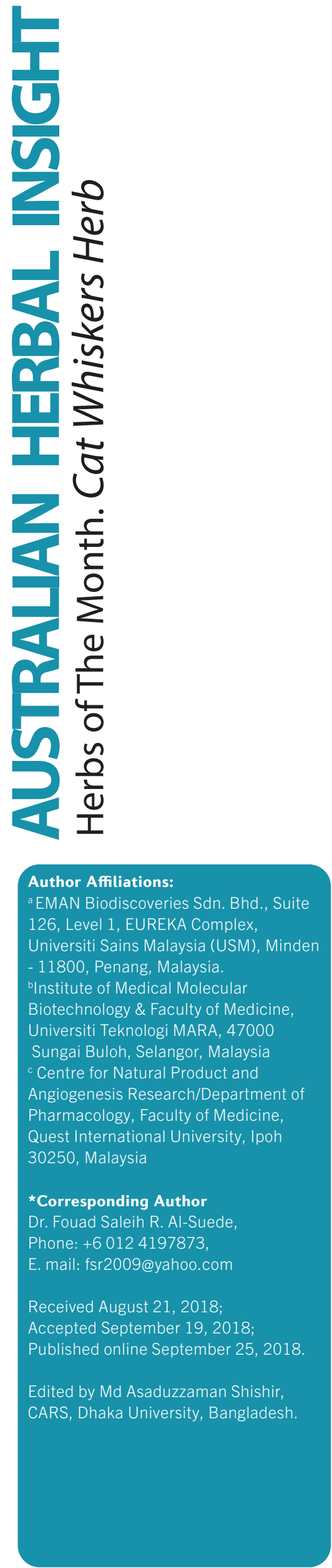

\title{
A Review on Cassia alata: Pharmacological, Traditional and Medicinal Aspects
}

Ranjanie Dewi ${ }^{\mathrm{a}}$, Yuhanis Firza ${ }^{\mathrm{a}}$, Mohammed Ali Nashiry ${ }^{\mathrm{b}}$ Fouad Saleih R. Al-Sue$\mathrm{de}^{\mathrm{a} *}$, Aman Shah Abdul Majid ${ }^{\mathrm{c}}$

\begin{abstract}
Herbalism has a long custom of utilization outside of conventional medication. It is winding up more standard as enhancements in examination and quality control alongside propels in clinical research demonstrate the estimation of natural medication in the treating and averting illness. World Health Organization has detailed that over $60 \%$ of individuals are relying upon traditional medication. Plants had been utilized for therapeutic purposes well before any history were even created. Herbal medicines are one sort of dietary supplement. They are sold as tablets, capsules, powders, teas, extracts, and new or dried plants. This article focuses to enhance and prepare a comprehensive review on pharmacological, medicinal and traditional value of Cassia alata plant. Cassia species are outstanding plant broadly dispersed in India and other tropical nations. Diverse parts of the plant (leaves, seed, and root) are presumed for their medicinal values. Several chemical compounds such as anthraquinone glycosides, naphthopyrone glycosides, phenolic compounds, flavonoids etc. have been isolated from this plant and well recognized traditional medicine as laxative and is effective for treatment of leprosy, ringworm infection, ophthalmic, skin diseases and liver disorders. The pharmacological, medicinal and traditional value reported in present review to confirm the therapeutic value of Cassia species to different developing countries. Therefore, this review may provide the compiled information which will guide to develop the novel agent for various disorders from Cassia species. Based on several scientific studies and review articles on Cassia alata species, this plant may suggest a gigantic biological potential.
\end{abstract}

Key words: Cassia alata, pharmacology, traditional medicine

\section{Introduction}

The World Health Organization (WHO) estimates $60 \%$ of individuals living in developing countries believe completely on ancient medicines for their health care (WHO 2000). However, The most important ingredients are obtained from medicinal plants. It has been discovered that majority of contemporary drugs are plant-derived therapeutic agents. In the United States, $78 \%$ of prescription drug are based on natural sources (Roberson 2008). This might be attributed to the very fact that several plants contain a phytochemicals that have found important applications within the field of human drugs. Natural products play a dominant role within the development of novel drug- leads for the treatment and cure of illness (Newman et al. 2003).

Senna alata (Figure 1), commonly named ringworm cassia as the plant leaves were used for treatment of ringworm. It is also, commonly named candle or bush empress candle plant, is so called due to the erect flower spikes when in bud appear like yellow candles.It is a tropical tree that typically grows to 4 $\mathrm{m}$ in height with horizontal branche. The fruits are straight, up to $25 \mathrm{~cm}$ long, black and winged pods. It is often used specifically as treatment against ringworm, fungicidal. It also has antibacterial, laxative, anti-inflammatory, anti-tumor, and diuretic properties (https://pfaf.org/user/Plant.aspx?LatinName=Senna + alata/14/10/2018). 


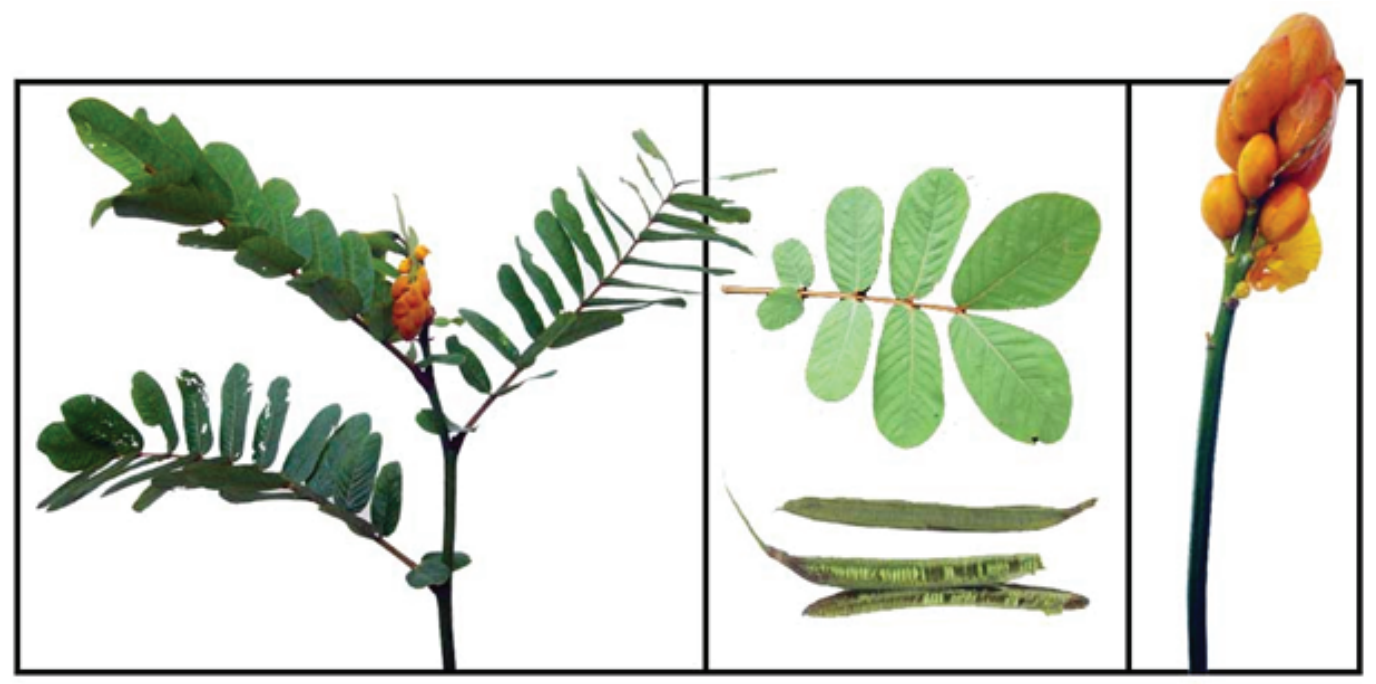

Figure 1 . Cassia alata (whole plant, flower and seeds) adopted from internet.

The purpose of this review is to update and provide complete knowledge of the traditional use, chemical constituent, pharmacological activities. Additionally, an elaboration with critical review for the performed experimental studies was made to justify evidences the traditional uses of Cassa alata and to recommend future studies and research.

\section{Ethnopharmacological Studies}

Complementary and alternative medicine is largely found in developing countries such as Africa and Asia. This is due to the fact that the people of these countries have their own way of healing via traditional herbs that has been practiced in their culture for ages (Nadimpalli 2017). Ranging from many particular species and sizes, Cassia plants are having plenty benefits for medicinal purposes. In traditional medicine, this plant has been recognized for its beneficial medicinal properties such as antimicrobial (Durapandiyan et al. 2006), antifungal (Makinde et al. 2007), purgative (Ral 1978) anti-inflammatory (Moriyama et al. 2003), analgesic (Belkin \& Fitzgerald 1952), antitumor (Paria 2005), It is called as Ringworm shrub and winged senna in English while in Sanskrit it is known as Dadrughna and Dvipagsti. Also in
Tamil, semaiagathi and Vandugolli is the name used for the plants by the locals. It has also famous with its common name for example, Candle bush, Emperor Candle stick, Christmas candle, Acapulo, Ringworm bush and Calabra bush. Apart from that, in Nigeria, the plant is famously known as घEwe Asunwon Oyinbo'. Wild senna (Cassia alata) is found in Ghana and Brazil, but it is now largely distributed in the United States of America and all over Africa, including Nigeria (Adelowo \& Oladeji 2017)

\section{Chemical Constituent}

Phytochemical studies are known as an assessment done in order to provide the scientific components and the therapeutic potency of a plant. Generally, the screening of the plants phytochemicals with healing potency has increased the interest of researchers on discovering type and amount of constituents of each medicinal plant. There is variety type of measures in the procedure of analyzing these phytochemicals screening.

For Cassia alata plant, it is reported that it contains variety of bioactive compound. It is also stated that, in the most recent studies, the identification and also the isolation of these therapeutic compounds of medicinal plants are important for specific disease
(Oladeji 2016). In order to promote Cassia alata as herbal medicine, thus the curative and the therapeutic effects must be studied.

The major component that has been isolated from the HPLC studies is known as ethyl acetate. This fraction was isolated with the aid of a combination of gel filtration and silica gel-based chromatography system. From the use of the spectroscopic analysis studies, there were two compounds derived from the ethyl acetate and n-butanol fraction which are identified as kaempferol and kaempferol 3-O-gentiobioside (Varghese et al., 2013).

There are major secondary metabolites of C. alata which has been notified and it has been reported to be flavonoids including kaempferol and its glycosides (e.g., kaempferol-3-O-gentiobioside and kaempferol-3-O- $\beta$-d-glucopyranoside), anthraquinones derivatives (e.g., alatonal, alatinone, chrysaphanol, emodin, rhein, aloe-emodin), essential oils, fatty acids and terpenoids (e.g., palmitic, oleic, linoleic acids, terpenoids ( $\beta$-sitosterol, stigmasterol, campesterol) and other metabolites for instance, ellagitannins and p-hydroxybenzoic acid (Hennebelle et al., 2009).

\section{Pharmacological Activities}


The antioxidant ability of acetone, ethanol and aqueous root extracts of Cassia alata was revised by measuring its DPPH and ABTS radical scavenging, its ferric reducing power and metal chelating activity, ferric reducing power. The ethanol extract possess high level of total phenolics and flavonoids with values of $78.21 \mathrm{mgGAE} / \mathrm{g}$ and 39.29 $\mathrm{mgQE} / \mathrm{g}$ and exhibited the simplest antioxidant activity within the $\mathrm{DPPH}$ and ABTS assays (IC50 = 45.18 and $39.14 \mu \mathrm{g} / \mathrm{mL}$ respectively). Additionally, the aqueous extract had more potent metal chelating and reducing power than the opposite extracts. These results counsel that Cassia alata root might function as new sources of antioxidants that may facilitate stop aerobic stress (Ita \& Ndukwe 2017).

\section{Anti-Inflammatory Activity}

In a study done by Sagnia et al. (2014) the impact of plant extracts on the cytokine production of $\gamma \delta \mathrm{T}$ lymphocytes was investigated. Isopentenyl pyrophosphate induced TNF-a production was reserved by plant extracts in a dose dependent manner. The best inhibition was obtained by $1 \mathrm{mg}$ of Cassia alata, . The impact of plant extracts on $\gamma \delta \mathrm{T}$ cells and immature dendritic cells (imDC) was revealed by the dose dependent reduction in TNF- $\alpha$ production within the presence of Cassia alata (Sagnia et al. 2014).

In the hexane extract of Cassia alata, the anti-inflammatory mechanism was studied in Complete Freund's Adjuvant (CFA) arthritis, as a chronic model of inflammation. The extract was administered to CFA arthritic animals at $500 \mathrm{mg} / \mathrm{kg}$. The CFA model was created by the injection of $0.5 \mathrm{ml} \mathrm{CFA}$ into the synovial cavity of the proper knee joint of hind leg of rats. Changes in knee joint swelling, cartilage integrity and synovial fluid leukocyte counts were assessed in response to Cassia alata treatment. Assessment of the reduction in hinge joint swelling was performed by getting the circumference of the knee joint. Histological analysis was done to assess the cartilage erosion. Cassia alata considerably ( $\mathrm{p}=0.009$ ) reduced knee joint swelling and provided protection against cartilage degradation. The migration of leukocytes to the blood $(\mathrm{p}=0.002)$ and secretion cavity $(\mathrm{p}=0.019,0.012,0.028$ and 0.002$)$ was conjointly considerably reduced. These results recommend potent anti-inflammatory activities for Cassia alata that would be probably exploited for arthritis therapy (Lewis \& Levy 2012).

\section{Antimicrobial Activity}

There are many studies done on anti-bacterial property of Cassia alata further (Sharma et al. 2015; Adedayo et al. 2001; Ibrahim \& Osman 1995). The antibacterial activity of Chloroform extract of the seed oil of Cassia alata and disc diffusion technique was used by Mannan et al. (2011) against pathogenic gram positive and negative bacterial. The extracts showed antibacterial activity at $0.1 \mathrm{ml} /$ disc concentration against Gram (-) bacteria and Gram (+) bacteria. Addiitonally, the seed oil extract showed $8 \mathrm{~mm}, 9 \mathrm{~mm}$ and $13 \mathrm{~mm}$ inhibition zone against Staphylococcus aureus, Bacillus cereu, Bacillus subtili, respectively, and $9 \mathrm{~mm}, 11 \mathrm{~mm}, 9 \mathrm{~mm}$, $10 \mathrm{~mm}$ and $12 \mathrm{~mm}$ zone of inhibition was shown against Gram (-) bacteri Shigella sonne, Pseudomonas aeruginosa, Salmonella typh, E. coli, Vibrio cholera.

Adedayo et al. (2001) investigatet crude and partially purified fractions of Senna alata flower against 22 bacterial strains. The reported the purified extract was nearly as effective as standard antibiotics, exhibiting zones of bacterial growth inhibition ranging from 10 to $25 \mathrm{~mm}$, even against multiple antibiotic resistant and not susceptible to methicillin, streptomycin and penicillin. A Additionally, a more recent study showed that acetone extract of root against clinically isolated B. subtilis and P. vulgaris (MTCC 441) whereas least activity was recorded in acetone extracts of root and stem against clinically isolated $\mathrm{S}$. aureus and $\mathrm{K}$. pneumoniae (MTCC 3384) ( Sharma et al. 2015). A previous study performed by Ibrahim \& Osman (1995) reported that the extract exhibited high activity against many species of dermatophytic fungi but low activity against non-dermatophytic fungi. It can be concluded that Cassia alata is the most potent species for having significant antimicrobial activity (Chatterjeesup et al. 2010).

\section{Anti-Obesity Study}

Cassia alata has additionally proven to exhibit anti-obesity property. In an exceedingly study done (Chichioco-Hern \& Leonido 2011) was stated that Cassia alata extracts considerably lowered body weight of mice. These plants were chosen on the idea of their phytochemical constituents. Methanol extract of Senna alata was evaluated for its hypolipidemic activity in diet-induced lipedema in mice Additionally, parametrial fat weight of mice was additionally reduced in a dose dependent (Chichioco-Hern \& Leonido 2011). Additionally, another study found that Cassia a alata leaf extract restores insulin sensitivity in high-fat diet-induced obese mice and reduced epididymal fat weight and adipocyte size (Naowaboot \& Piyabhan 2017)).

\section{Hepatoprotective Study}

Hepatoprotective activity of the alcoholic extract (95\%) of the dried leaves of ringworm Cassia alata (ECA) was studied against Paracetamol induced hepatic injury in albino rats. 
Pretreatment of the ECA reduced the biochemical markers of hepatic injury like serum glutamate pyruvate transaminase (SGPT), serum oxaloacetate transaminase (SGOT), alkaline phosphatase (ALP), total bilirubin and gamma glutamate transpeptidase (GGTP). Histopathological observations additionally disclosed that pretreatment with ECA protected the animals from paracetamol induced liver damage. The results indicate that the leaves of Cassia alata possess the hepatoprotective activity. This property is also attributed to the flavonoids present within the leaves of Cassia alata. Lastly, the current study demonstrated that the ECA of the dried leaves of ringworm Cassia possesses hepatoprotective activity. Additionally, the hepatoprotective property is also attributed to the active principles of the plant particularly, flavonoids, tannins and alternative polyphenolic compounds (Ramasamy et al. 2009).

\section{Toxicology Studies}

Although many studies have evaluated the pharmacological effects of Cassia alata, few data are obtained concerning its toxicity. Igbe and Edosuyi (2016) conducted studies to determine the toxicological effects of Cassia alata extract flower in Wistar rats at doses of 100, 400 and 800 $\mathrm{mg} / \mathrm{kg}$ by oral administration for 4 weeks. The extract significantly $(\mathrm{P}<0.05)$ elevated the platelets, monocytes, lymphocytes, granulocytes counts at doses of 400 and 800 $\mathrm{mg} / \mathrm{kg}$ in the female rats. No significant changes were observed between treated rats and control in the biochemical parameters, relative organ weight and body weight, lipid profile. Additionally, histological sections of spleen, kidney, liver, heart and lung did not show remarkable changes or gross pathological changes at all doses. Thus, they suggested that the aqueous extract of C. alata flower is relatively safe when administered orally in rats. In contrast to this, another study was carried out by Amao et al. (2010) and showed that orally administered methanolic extract of cassia alata into rats induced lethargy and chronic inflammatory responses. The used doses in this study were extremely high $(50,100$ and $150 \mathrm{~g} / \mathrm{k}$ ) so these results are expected and logically acceptable. Furthermore, Pieme et al. (2006) investigated the acute and subacute toxicities of Cassia alata in Wistar albino rats and Swiss mice. Six groups of mice were treated by intra-gastric gavages $0,4,8,12,16,20$ times $1000 \mathrm{mg} / \mathrm{kg}$ dose of hydro-ethanolic extract of leaves of Cassia alata. Distilled water was used as the negative control. $20 \%$ liver homogenates and blood samples were collected at the end of the treatment after 26 days. The medium lethal dose (LD50) was about $18.50 \mathrm{~g} / \mathrm{kg}$ of body weight. There was significant changes of body weight and some biochemical index of serum and $20 \%$ liver homogenates (Aspartate aminotransferase (AST), alkaline phosphatase (APL), glutathion), and haematological parameters (platelets). Additionally, the extract seems to ameliorate the liver architecture.

\section{Cardiovascular Effect}

Among the effect of Hyperglycemia induced oxidative stress as well as many other health complications in diabetes such as the cardiac dysfunction. The study conducted reveals the therapeutic effect of Cassia alata leaf aqueous extract on oxidative stress in aorta as well as heart of streptozotoc in hyperglycemic rats (Ishak et al. 2015).

In order to reduce the oxidative stress, the antioxidant enzymes in hyperglycemic state needed an extra mechanism. Cassia alata is a plant that has been proved to exhibit an efficient anti-oxida- tive mechanism. This may perhaps increase the rate of the oxidative stress and expression of antioxidant enzymes. The contents of phenolic in the plant were identified as exhibiting an antioxidant effect for the activity in reducing the oxidative stress. To be concluded in the experiment, Cassia alata has significantly reduced Malondialdehyde (MDA) levels and also it has increased antioxidant activity, and also, it helps in lowering the blood glucose level. Therefore, Cassia alata could also be effective therapeutic treatment against oxidative stress induced cardiac dysfunction in hyperglycemia and as well as anti-diabetic functions.

\section{Cytotoxicity Effect}

The cytotoxicity effect of different extraction of Cassia alata had been investigated. The cytotoxicity effect of Chloroform fraction of leaves was assessed by MTT assay against three human cancer cell lines MDA-MB-231, HepG2 and Caco2 (Mohammed et al. 2017). A remarkable cytotoxicity was observed against HepG2 IC50 $=37.4 \mu \mathrm{g} / \mathrm{ml}$ at treatment time $48 \mathrm{~h}$, whereas weak toxicity effect on MDA-MB-231 and Caco2 cells with IC50 values $>100 \mu \mathrm{g} / \mathrm{ml}$. The anticancer activity against HepG2 cells was possibly attributed to anthraquinones content (Mohammed et al. 2017). Levy and Lewis (2011) investigated the cytotoxic effects of hexane extract of the plant leaves in A549 lung cancer cells. The MTT assay was used and the IC50 values were 143 microg/ml. The toxicity effect was mediated by caspase 8 activation which may attributable to kaempferol. Thecytotixicity of hydromethanolic leaf extract (HMLE) of Cassia alata was avaluated by the WST-1 assay by using K562 leukaemia cell line (Adebesin et al. 2013). The CC50 values was $104.5 \pm 3.35 \mu \mathrm{g} / \mathrm{ml}$ which 
approaching the CC50 value of the herbal control drug Nicosan (115.3 $\pm 1.99 \mu \mathrm{g} / \mathrm{ml}$ ).

\section{Anti-Diabetic Effect}

When the body failed to produce the sufficient amount of insulin or a resistance towards insulin is developed is known as diabetes mellitus (DM). With the condition of high level of blood glucose, it will lead to a variety of disease conditions such as stroke, kidney failure, blindness, limb amputations, heart diseases, and birth defects. .

It is also stated that Cassia alata has one of the most outstanding anti-diabetic effect in Africa, (Abo et al. 2008). Apart from that, it is famous in the island of Caribbean (Giron et al. 1991) and also in India (Khan \& Yadava 2010). Through the previous studies done by the researchers, some preliminary in vivo studies have been conducted to confirmed the antidiabetic potential of the $85 \%$ ethanol leaves extract as a reducer of the blood sugar level in the streptozotocin-induced hyperglycemic animals (Palanichamy et al. 1988). Kazeem et al. 2015 studied the effects of Cassia alata leaf extracts by oral administration into the sucrose-induced hyperglycemic Male wistar rats. The results showed a significant reduction in the postprandial blood glucose level. Additionally, Kazeem et al. 2015 found that both hexane and acetone extracts inhibited $\alpha$-glucosidase and $\alpha$-amylase in vitor in a competitive and uncompetitive manner respectively.

However there are large numbers of chemical components identified from Cassia alata. The active component responsible for the anti-diabetic properties of the plant was not known. Therefore from the study done by Varghese et al. (2013) stated that kaempferol and the major glyco- side kaempferol-3-O-gentiobioside from the ethyl acetate and n-butanol fractions respectively displayed a moderate level of anti- $\alpha$-glucose-inhibitory activity in the activity of Cassia alata.

It is also concluded by Verghese et al. (2013) that by using a major carbohydrate digestion enzyme, a-glucosidase, revealed that Cassia alata showed an anti-diabetic ability. The reputed use of the plant could therefore be partly attributed due to this mechanism of action.

\section{Conclusions and future directions}

Several chemical compounds like anthraquinone glycosides, naphthopyrone glycosides, phenolic compounds, flavonoids etc. are isolated from cassia species plants. These chemical compounds are indicators for pharmacological activities like hepatoprotective, anti-inflammatory drug, antigenotoxic, hypolipidemic, spasmogenic and antinociceptive, antiproliferative, hypotensive, purgative, antidiabetic, estrogenic and antiestrogenic, antiulcer, antioxidant, antifungal, antishigellosis, anthelmintic, antimutagenic, antibacterial and antiplasmodial. There is no doubt that these plant species are reservoir of potentially helpful chemical compounds which may function a drug, as newer leads and clues for modern drug style by synthesis. It's thought that thorough data as conferred during this review on pharmacological, traditional and medicinal values of Cassia species could offer sturdy proof for the employment of this plant in numerous medicines.

In conclusion, this study has given strong proof that Cassia alata will exhibit properties like stated above. The scientific studies and review articles on Cassia species represents an enormous biological potential of those plants. Pharmacological, medicinal and traditional studies with standardized extracts and isolated constituents got to be performed to analyze unexploited potential of this plant.

\section{References}

Abo K, Fred-Jaiyesimi A, Jaiyesimi A. Ethnobotanical studies of medicinal plants used in the management of diabetes mellitus in South Western Nigeria. Journal of ethnopharmacology. 2008;115(1):67-71. Adebesin O, Okpuzor J, Iroanya O, Adenekan S, Aniekwena C. Antioxidant and cytotoxic properties of Senna alata and Senna podocarpa leaf extracts. Planta Medica. 2013;79(13):PA27.

Adedayo O, Anderson W, Moo-Young M, Snieckus V, Patil P, Kolawole D. Phytochemistry and antibacterial activity of Senna alata flower. Pharmaceutical biology. 2001;39(6):408-12.

Adelowo F, Oladeji O. An overview of the phytochemical analysis of bioactive compounds in Senna alata. Am J Chem Biochem Eng. 2017;2:7-14.

Amao S, Ajani R, Oladapo O. Cassia alata alters liver structure in rat. African Journal of Biomedical Research. 2010;13(3):231-3.

Amao S, Ajani R, Oladapo O. Cassia alata alters liver structure in rat. African Journal of Biomedical Research. 2010;13(3):231-3.

Belkin M, Fitzgerald DB. Tumor-damaging capacity of plant materials. I. Plants used as cathartics. Journal of the National Cancer Institute. 1952;13(1):139-55.

Chatterjeesup S, Chatterjeesup S, Dutta S. A survey on VAM association in three different species of Cassia and determination of antimicrobial property of these phytoextracts. Journal of Medicinal Plants Research. 2010;4(4):286-92.

Chichioco-Hern CL, Leonido FMG. Weight-lowering effects of Caesalpinia pulcherrima, Cassia fistula and Senna alata leaf extracts. Journal of Medicinal Plants Research. 2011;5(3):452-5.

Duraipandiyan $\mathrm{V}$, Ayyanar M, Ignacimuthu S. Antimicrobial activity of some ethnomedicinal plants used by Paliyar tribe from Tamil Nadu, India BMC complementary and alternative medicine. 2006;6(1):35.

Girón LM, Freire V, Alonzo A, Cáceres A. Ethnobotanical survey of the medicinal flora used by the Caribs of Guatemala. Journal of Ethnopharmacology. 1991;34(2-3):173-87. 
Girón LM, Freire V, Alonzo A, Cáceres A. Ethnobotanical survey of the medicinal flora used by the Caribs of Guatemala. Journal of Ethnopharmacology. 1991;34(2-3):173-87.

Hennebelle T, Weniger B, Joseph H, Sahpaz S, Bailleul F. Senna alata. Fitoterapia. 2009;80(7):385-93. https://pfaf.org/user/PIant. aspx? Latin Name=Senna+alata/14/10/2018.

Ibrahim D, Osman $\mathrm{H}$. Antimicrobial activity of Cassia alata from Malaysia. Journal of ethnopharmacology. 1995;45(3):151-6.

Igbe I, Edosuyi O. Toxicity profile of aqueous extract of Cassia alata flower in Wistar rats. Journal of Pharmacy \& Bioresources. 2016;13(2):92-102.

Ishak R, Abu IF, Lajis HM, Ambia KM, Noah RM. Effects of cassia alata treatment towards cardiovascular oxidative stress in hyperglycemic rats. International Journal of Pharmaceutical Sciences Review and Research. 2015;34(2):254-8

Kazeem MI, Azeez GA, Ashafa AO. Effect of senna alata ( $L$ ) roxb (fabaceae) leaf extracts on alpha-amylase, alpha-glucosidase and postprandial hyperglycemia in rats. Tropical Journal of Pharmaceutical Research. 2015;14(10):1843-8. Khan MH, Yadava P. Antidiabetic plants used in Thoubal district of Manipur, Northeast India. 2010.

Levy A, Lewis A. Cassia alata leaf extract induces cytotoxicity in A549 lung cancer cells via a mechanism that is caspase 8 dependent. West Indian Medical Journal. 2011;60(6):608-14.

Lewis AT, Levy AS-A. Anti-inflammatory activities of Cassia alata extract in Complete Freund's Adjuvant arthritis in rats. Federation of American Societies for Experimental Biology; 2012.

Makinde A, Igoli J, Ta'Ama L, Shaibu S, Garba A. Antimicrobial activity of Cassia alata. African journal of biotechnology. 2007;6(13).

Mannan A, Kawser MJ, Ahmed AA, Islam NN, Alam SM, Khan MAE, et al. Assessment of antibacterial, thrombolytic and cytotoxic potential of Cassia alata seed oil. Journal of Applied Pharmaceutical Science. 2011;1(9):56. Mohammed AR. Phytochemical, cytotoxicity and antioxidant investigation of Cassia alata leaves growing in Egypt. Journal of Innovations in
Pharmaceutical and Biological Sciences. 2017; I (4), 97-105

Moriyama H, lizuka T, Nagai M, Miyataka H, Satoh T. Antiinflammatory activity of heat-treated Cassia alata leaf extract and its flavonoid glycoside. Yakugaku Zasshi. 2003;123(7):607-11.

Nadimpalli S. Should the use of complementary and alternative medicine be restricted? International Journal of Basic \& Clinical Pharmacology. 2017;5(5):1691-4.

Naowaboot J, Piyabhan P. Senna alata leaf extract restores insulin sensitivity in high-fat diet-induced obese mice. Clinical Phytoscience. 2017;2(1):18.

Ita, B N., G.I. Ndukwe, G.I. 2017. Antioxidant Activity of Senna alata Root Extracts

Ita Gloria Ihuoma NdukweGloria Ihuoma Ndukwe. Journal of Natural Products and Resources. 3(1):94-96

Newman DJ, Cragg GM, Snader KM. Natural products as sources of new drugs over the period 1981- 2002. Journal of natural products. 2003;66(7):1022-37.

Oladeji SO. Thin-layer chromatographic analysis of flavonoids and total phenolics in methanolic and ethanolic extracts of Senna alata (L.) Roxb.(Fabales: Fabaceae). Brazilian Journal of Biological Sciences. 2016;3(5):221-5.

Organization WH. General guidelines for methodologies on research and evaluation of traditional medicine. Geneva: World Health Organization, 2000. Palanichamy S, Nagarajan S, Devasagayam M. Effect of Cassia alata leaf extract on hyperglycemic rats. Journal of ethnopharmacology. 1988;22(1):81-90. Paria N. Medicinal plant resources of south West Bengal: Research Wing, Directorate of Forests, Government of West Bengal, in collaboration with Department of Environment, Government of West Bengal; 2005

Pieme C, Penlap V, Nkegoum B, Taziebou P, Tekwu E, Etoa F, et al. Evaluation of acute and subacute toxicities of aqueous ethanolic extract of leaves of Senna alata (L.) Roxb (Ceasalpiniaceae). African Journal of Biotechnology. 2006;5(3):283-9.

Ral P. Anthracene derivatives in leaves and fruits of Cassia alata. Current science. 1978.

Ral P. Anthracene derivatives in leaves and fruits of Cassia alata. Current science. 1978.

Ramasamy A, Balasundaram J, Rajappan M. Hepatoprotective activity of the alcoholic extract of the dried leaves of Cassia alata, Linn. Journal of pharmacy research. 2009;2(6):1107-9.

Roberson E. Nature's pharmacy, our treasure chest: Why we must conserve our natural heritage. Center for Biological Diversity. 2008.

Sagnia B, Fedeli D, Casetti R, Montesano C, Falcioni G, Colizzi V. Antioxidant and anti-inflammatory activities of extracts from Cassia alata, Eleusine indica, Eremomastax speciosa, Carica papaya and Polyscias fulva medicinal plants collected in Cameroon. PloS one. 2014;9(8):e103999.

Sharma P, Pandey D, Rizvi A, Gupta A. Antimicrobia activity of Cassia alata from Raipur region against clinical and MTCC isolates. Int J Curr Microbiol App Sci. 2015;4(1):330-9.

Varghese GK, Bose LV, Habtemariam S. Antidiabetic components of Cassia alata leaves: Identification through a-glucosidase inhibition studies. Pharmaceutical biology. 2013;51(3):345-9. 